\title{
De Se ExCEPTIONALISM ANd Frege Puzzles
}

\author{
JAMES R. SHAW \\ University of Pittsburgh
}

\begin{abstract}
De se exceptionalism is the view, notably championed by Perry (1979) and Lewis (1979), that our characteristically 'first-personal' ways of thinking about ourselves present unique challenges to standard views of propositional attitudes like belief. Though the view has won many adherents, it has recently come under a barrage of deserved criticism. A key claim of detractors is that classic examples used to motivate de se exceptionalism from de se ignorance or misidentification are nothing more than familiar Frege-puzzles, which raise no issues exclusive to self-directed thought. After reviewing how this simple objection has substantial force against the classic defenses of exceptionalism, I provide new arguments based on cases of pure de se ignorance that avoid the criticism. Afterward, I revisit Lewis's defense of exceptionalism, diagnosing how he arrived at roughly the right conclusions on the basis of an argument that begged critical questions and obscured the representationally unique features of the de se.
\end{abstract}

Everyone intuitively has (at least) two ways of thinking about themselves. This is clearest when someone forgets who they are. An amnesiac Trump might observe himself on television thinking the thought he would express by saying "that man is president." But he may have yet to form the seemingly distinct thought he would express by saying "I am president." Both thoughts appear to be about Trump. But only the second would be held in a characteristically first-personal way. The latter kind of cognition is sometimes termed de se thought.

De se thought appears to have some unique properties. Descartes, among others, took it to be epistemically special: self-directed thought was, for him, a special source of irrefragable judgments. But philosophers of language and mind have been drawn to de se thought because it may be semantically special-special in terms of what, or how, it represents. The seminal work of Perry (1979) and Lewis (1979) made the influential case that de se thought poses a special challenge to our understanding of the representational properties of propositional attitudes like belief or desire-special in the sense that de se attitudes uniquely pose this

Contact: James R. Shaw <James.A.R.Shaw@gmail.com> 
kind of challenge. For a time this de se Exceptionalist view enjoyed substantial assent. ${ }^{1}$

But, especially in recent years, a barrage of criticism has been leveled against the position by de se sKeptics-those who deny that de se attitudes pose any special challenge for understanding propositional attitudes. ${ }^{2}$ A key contention of several skeptics is that standard examples of de se ignorance or misidentification used to motivate de se exceptionalism bear a very close resemblance to classic puzzles for attitudes raised by Frege (1892/1997). We can easily raise these latter 'Frege puzzles' without any special first-personal way of thinking about objects, casting doubt on whether there could be any special puzzle for attitudes raised by de se thought. ${ }^{3}$

I sympathize with skeptics insofar as they claim that the classic defenses of exceptionalism have been unclear and ultimately unpersuasive. But, for all that, I think that appeals to de se ignorance to motivate a special problem for attitudes were roughly on the right track after all. After reviewing how the initial engagement plays out between the exceptionalist and skeptic in $\S 1, I^{\prime} l l$ argue in $\S \S 2-4$ that modifications of an example of Lewis (1979) can be used to create a powerful argument against a simple and attractive view of mental content. The modifications force us to confront the question of whether, and how, an instance of de se ignorance could be resolved by the sharing or transfer of a belief. The pressure created by these arguments exploiting questions of sharing and transfer is not replicable with more familiar Frege puzzles. As such, de se exceptionalism stands. Even so, the pressure of detractors will turn out to be essential in helping to clarify what exactly the problem posed by the de se is supposed to be.

Mine is not the only recent attempt to revamp arguments for de se exceptionalism. One important feature of my arguments is that they are 'purely informational', and so contrast with some prominent defenses of exceptionalism (notably Ninan, 2016; Torre, 2018) that crucially draw on assumptions about the role of attitudinal content in explaining action. ${ }^{4}$ Such assumptions are controver-

1. The terminology of 'de se exceptionalism' and 'de se skepticism' is drawn from Ninan (2016). Perry and Lewis's work is of course influenced by the work of Castañeda (1966, 1967, 1968), not to mention Frege (1918/1997).

2. For works at least roughly suggesting this line see Boer and Lycan (1980), Spencer (2007), Cappelen and Dever (2013), Devitt (2013), Douven (2013), Magidor (2015).

3. This is by no means the only concern that detractors have raised. For example, Cappelen and Dever (2013) have seemingly argued for the much more radical conclusion that there are no such things as distinctively de se attitudes. I sympathize with the defense of Ninan (2016, 88-91) against such a view. But more generally I do not mean to survey, let alone address, every challenge to de se exceptionalism here. I will content myself with responding to a central worry for classic cases.

4. See, e.g., the Explanation principle of Ninan (2016), or the critical third premise linking content and action in the defense of the thesis Content Determines De Se Belief (CDDS) from Torre (2018). 
sial. Even if they weren't, they might become so in light of the arguments for exceptionalism. A distinguishing feature of my arguments is that they bypass such assumptions and show that probing the nature and resolution of de se ignorance is itself sufficient to establish exceptionalism. ${ }^{5}$

\section{De Se Exceptionalism and De Se Ignorance}

I noted that de se attitudes rise to prominence when someone loses track of who they are, or what they are like, in a characteristically first-personal way. No wonder, then, that precisely such cases of de se ignorance have been exploited to highlight what makes de se attitudes semantically special.

Consider two cases from Perry.

\section{The Messy Shopper}

I [Perry] once followed a trail of sugar on a supermarket floor, pushing my cart down the aisle on one side of a tall counter and back the aisle on the other, seeking the shopper with the torn sack to tell him he was making a mess. With each trip around the counter, the trail became thicker. But I seemed unable to catch up. Finally it dawned on me. I was the shopper I was trying to catch. (Perry, 1979, 1)

\section{Lingens THe AmNesiaC}

An amnesiac, Rudolf Lingens, is lost in the Stanford library. He reads a number of things in the library, including a biography of himself, and a detailed account of the library in which he is lost .... He still won't know who he is, and where he is, no matter how much knowledge he piles up, until that moment when he is ready to say, "This place is aisle five, floor six, of Main Library, Stanford. I am Rudolf Lingens." (Perry, 1977, 492)

Or a further case from Lewis.

5. Some prominent exceptionalists like Ninan (2016) openly concede the failure of the case for de se exceptionalism from examples of de se ignorance, as in Perry's Messy Shopper and Lewis's Two Gods discussed below. After rehearsing the arguments of skeptics, Ninan concludes:

These considerations suggest that there is no clear route from these sorts of cases [i.e., puzzles of de se ignorance] to the distinctive problem of de se attitudes. The de se exceptionalist should seek that problem elsewhere. $(2016,96)$

Ninan does concede in a footnote (fn. 14) that he is open to having his judgement here overturned. 


\section{Two Gods}

[Two gods] inhabit a certain possible world, and they know exactly which world it is. Therefore they know every proposition that is true at their world. Insofar as knowledge is a propositional attitude, they are omniscient. Still I can imagine them to suffer ignorance: neither one knows which of the two he is. They are not exactly alike. One lives on top of the tallest mountain and throws down manna; the other lives on top of the coldest mountain and throws down thunderbolts. Neither one knows whether he lives on the tallest mountain or on the coldest mountain; nor whether he throws manna or thunderbolts. (Lewis, 1979, 20-1)

Intuitively what Perry comes to have, and what Lingens and Lewis's gods yearn to acquire, are new de se attitudes.

What it is to come to have these new attitudes is disputed. Perry, for example, argued from his cases that we must accommodate special self-directed attitude states (like belief states) and not necessarily a new kind of content or proposition. When Perry learns that he is the shopper with the torn sack, he comes to believe a content he may well have already believed (that Perry is the shopper with the torn sack) but if so he has a new kind of belief state that relates to that proposition-a first-personal one that has distinctive ties to agency.

By contrast, Lewis concluded from these cases that we should enrich the objects of attitude states, accommodating objects of belief that can vary in their truth (or correctness) from time to time and person to person. On this view, when Perry learns that he is the shopper with the torn sack, he must come to believe a new proposition that he didn't believe before-one that is true 'of him', but may be false of anyone else in the possible world Perry occupies. ${ }^{6}$

Does the de se skeptic deny these lessons? Perhaps. But what is integral to a skeptic's position, as I characterize it, is that they endorse the following conditional: if the above cases force us to accept some such lessons, then other cases not involving de se attitudes do so independently, and for broadly the same reasons. Some detractors will use this conditional in a modus tollens, and others will not. What I want to understand here are the grounds for thinking the conditional holds.

To see the concern, we needn't focus on any particular argument that the de se exceptionalists have given, or any particular lesson they have drawn. This is because there seems to be a parallel between the cases above, and ordinary cases of ignorance of identity, or misidentification, that have little to do with first-person thought.

6. Technically, Lewis reserves the term "proposition" for an object of attitudes that distinguishes between no more than worlds. I won't follow him in this usage. 
Consider the variant on Perry's Messy Shoppen, offered by Cappelen and Dever (2013):

\section{Messy Superman}

Pushing my cart down the aisle I was looking for Clark Kent to tell him he was making a mess. I kept passing by Superman, but couldn't find Clark Kent. Finally, I realized, Superman was Clark Kent. I believed at the outset that Clark Kent was making a mess .... But I didn't believe that Superman was making a mess. That seems to be something that I came to believe. And when I came to believe that, I stopped looking around and I told Superman to clean up after himself. My change in beliefs seems to explain my change in behavior. (Cappelen and Dever, 2013, 33)

Here we have a familiar form of ignorance of identity. We have two ways of knowing a person (as Clark Kent, or as Superman), and an agent who doesn't recognize they are ways of knowing a single person. The critical question is: what could we possibly learn from Perry's Messy Shopper about attitudes that we won't also learn from Messy Superman? In both cases, there appear to be two ways of thinking about one individual, ignorance of that fact, and a resolution of that ignorance that bears on an agent's activities. What does it matter that there is a 'first-personal' way of thinking in one case but not another? It is not obvious what the important difference could be.

Consider another comparison drawn by Magidor (2015). Lewis seems to reason in the following way about Lingens and the two gods: they know, or are in a position to know, the propositions (or at least the relevant propositions) whose truth is invariant within a world, but they are still not in a position to know some further thing. So that thing must be an object of knowledge whose truth varies within a world.

Magidor notes that the argument here seems to trade on Lewis's highly controversial conception of propositional content, according to which propositions are individuated by the worlds in which they are true. Once this is acknowledged, we can pressure the Lewisian argument with variants like the following.

\section{Astronomical Novice Lingens}

Suppose ... the Stanford library has a book which contains all the true propositions concerning Hesperus. On the face of it, Lingens could read the whole book and still fail to know whether Phosphorus is a planet. (Magidor, 2015, 255)

How could this be? Well, since Lewis endorses the possible worlds conception of content, according to which two propositions are identical if they are true 
at the same metaphysically possible worlds, the proposition that Phosphorus is a planet can apparently be expressed in English with "Hesperus is a planet", which is of no help to Lingens. Once we realize any given proposition about Phosphorus can be expressed by several sentences of English that express the same truth-conditions at metaphysically possible worlds, it is not clear that Lingens's ignorance will necessarily be resolved by his book. As a result, "... Lewis also needs to account for the lingering ignorance in this case, even though it has nothing in particular to do with de se attitudes, and the move to [accommodate propositions whose truth varies within a world] does nothing to help here" (Magidor, 2015, 255).

The concern is that the problems for theories of propositional attitudes raised by Lingens the Amnesiac and Two Gods may simply be the much more general problems raised when an agent is unaware that two objects are in fact one. This concern might be diminished if Lewis had some account of Frege's classic puzzles that failed to cover the cases of Lingens or the two gods. But, as Magidor rightly notes: "It is ... far from clear that the possible-worlds account has some simple solution to the Hesperus/Phosphorus puzzle, one that is not available for I/Lingens case" $(2015,256) .{ }^{7}$

Roughly the same criticisms have been made by a number of other authors. Cappelen and Dever, taking a similar line, assert that "the kinds of cases that have been made famous by Perry and others pattern with (indeed, are instances of) standard Frege cases ..." $(2013,59)$. On this view, "attitudes de se are simply attitudes de their owners" (Boer and Lycan, 1980, 432) and it becomes a bit of a mystery why anyone thought there was anything semantically special about de se attitudes to begin with. Indeed, the mystery is compounded in that Frege himself is, to all appearances, a de se exceptionalist-holding that each person's self-directed thoughts are proprietary and inherently unshareable (Frege, 1918/1997). ${ }^{8}$ Exactly why Frege seems to hold this view is a topic I won't be able to enter into here. ${ }^{9}$ Still, it would be an interesting surprise if the originator of puzzles of informative identity hadn't recognized those puzzles when he effectively ran up against them again, in only slightly altered form.

7. For the record, and as may become important if de se exceptionalism holds, I do think that the possible worlds theorist has a viable theory of de re ignorance, ascription, and communication that does not easily extend to de se cases without the help of Lewis's proposed refinement of content. See Shaw (2015). But even if this is right, Magidor's point is still forceful: it would be a substantial concession if de se exceptionalism could only be motivated on a small class of controversial theories of attitude reports.

8. For views that develop or incorporate aspects of Frege's position see Evans (1981), McDowell (1984), Heck (2002), and Chalmers (2011).

9. For some pertinent discussion see, e.g., Perry (1977), Evans (1981), Kripke (2011). 


\section{De Se Ignorance and Time}

I won't delve deeper into this dialectic. There is in fact much more to be said to bolster the skeptics' position. But I want to concede much of the force of their objections. As such, a rough sketch of their position will suffice to appreciate the arguments to follow. Each draws on slight variants of Lewis's Two Gods. Once I've laid out and discussed all the cases, I'll return in \$5 to consider what may have been problematic in Lewis's original presentation, and the defenses of de se exceptionalists more generally.

I should add, before beginning, that it is probably best to think of de se exceptionalism as a thesis that can be established in degrees, depending both on how many theorists are pressured by de se cognition to amend their theories, as well as on how significant the amendments are. The goal in what follows is to show that we should adjust a quite broad class of theories of mental content to give thoughts about time and 'oneself' a perspectival character that has no analogous motivation from Frege puzzles generally. The most natural adjustments of this kind may vary from theory to theory. As such, the arguments will of necessity apply pressure to a collection of theses governing mental content, rather than any single doctrine. Let me begin by formulating the theses in question.

By a proposition, I mean to denote an abstract truth-evaluable object of attitudes like belief or desire. ${ }^{10}$ Call a proposition timeless if its truth does not vary from time to time, and time-sensitive otherwise. ${ }^{11}$ Call a proposition temporally indiscriminate if whenever an agent can think that proposition at some time, it is in-principle possible for that agent to think that proposition at any other time. Call the proposition temporally discriminate otherwise. ${ }^{12}$

I'll use cases of de se ignorance to apply pressure to the conjunction of three natural assumptions about attitudes and mental content. ${ }^{13}$

10. Or perhaps a 'correctness-evaluable' abstraction, in case truth is not the right notion to apply to a proposition whose applicability varies from time to time or person to person.

11. To clarify, a proposition is timeless if its truth-value does not vary from time to time within a possible world-that is, a total world-historical state. Focusing on total world-historical states allows us to ask whether propositions have a sensitivity to time that is to some extent separate from metaphysical questions in the philosophy of time.

12. The qualification that it be 'in-principle' possible to think the proposition at other times is meant to bracket cases where, for example, an agent is conceptually impoverished at the other times (for example, as a child might be). The notion of trans-temporal accessibility is admittedly left a little vague. For all that, I think it is clear enough to appreciate and evaluate the arguments to follow.

13. Compare the assumptions considered for attack by the de se exceptionalist in Perry (1979), Ninan (2016). 


\section{Binary Relationalism (about Attitudes)}

An attitude like belief is a binary relation between an agent and a proposition, not grounded in any attitude state of higher adicity.

\section{Timelessness (of Mental Content)}

The propositional objects of attitudes are timeless.

\section{Temporal Indiscriminateness (of Mental Content)}

The propositional objects of attitudes are temporally indiscriminate.

Binary Relationalism has some claim to being the standard view of propositional attitudes, though it is worth flagging that it is nonetheless controversial. It contrasts with TeRnARY ReLATIONALism. On the latter view, belief is a ternary relation between an agent, a proposition, and a mode of presentation, or is a binary relation grounded in such a ternary relation. I will argue in $\$ 3$ that BINARY Relationalism is inessential to the arguments to follow: the real targets are Timelessness and Temporal Indiscriminateness. Still, Binary Relationalism will help as a simplifying assumption to get started. ${ }^{14}$

Let's begin with a case similar to Lewis's Two Gods, but where we have a single agent ignorant not of who they are, but what time it is. ${ }^{15}$

\section{Forgetful Lethe}

14. Both Perry and Lewis treat time as a dimension along which the unique features of de se thought manifest themselves. Subsequent exceptionalists have tended to followed suit, and time has been critical to the development of frameworks that integrate exceptionalist elements, like those for doxastic updating that grow out of Elga (2000). But exceptionalist treatments of time call for some important qualifications, as some such treatments can be motivated without considering self-directed thought. For example, one response to the puzzle developed below is to follow Lewis and take attitudinal content to involve a relation to time-sensitive objects. But one could motivate this conclusion about mental content in different ways having nothing to do with thoughts about the self: for example, by consideration of the proper treatment of linguistic tense, including the semantics of attitude verbs taking tensed complements, or the nature of agreement and disagreement over time (cf. the literature growing out of Richard, 1981, including Brogaard, 2012), or as a result of particular theses about the metaphysics of time. What is distinctive about the exceptionalist position is not (or not necessarily) its treatment of time in relation to mental content, but the route by which that treatment is established. The argument to follow is one that is established independently of (for example) our views of tense or of the metaphysics of time. The exceptionalist claim is that mere consideration of self-directed thought motivates adjustments to our views of mental content. This is significant since the exceptionalist arguments should generalize to 'personhood' in ways that non-exceptionalist arguments for related treatments of time will not (see $\$ 4$ ).

15. The case will be reminiscent of the much discussed case of SLEEPING BEAUTY popularized by Elga (2000), that raises questions about how de se beliefs should be integrated into formal theories of belief change. 
The god Lethe finds omniscience dreary. On Sunday night he sets things up so that the following will occur: He will wake Monday in an isolated room and spend the day there. Monday night he will drink a tea that will put him to sleep, and erase his memories of that entire day. The amnesia will last for the duration of the next dayTuesday. He will wake on Tuesday at the same time he awoke on Monday and (because his internal states will be 'reset' by the tea) will end up performing the exact same activities throughout the course of the day. That night he will drink another cup of tea that has no special properties, but which is indistinguishable in taste from the amnesiainducing tea. He will wake up on Wednesday with his memories of Monday restored.

What occurs in intuitive terms, if the story is coherent, is that Lethe is omniscient on Sunday, but becomes ignorant on Monday and Tuesday of whether it is Monday or Tuesday. After all, Lethe's subjective experiences on Monday will be the very same as those he has on Tuesday. When Wednesday arrives, and Lethe's memories are restored, he is in a position to know what day it is again. At that point, intuitively, his omniscience has returned.

As noted, Forgetful Lethe differs from Lewis's Two Gods in that the former concerns ignorance of what time it is rather than ignorance of who one is. We'll see in $\S 4$ that this difference can be erased. But there is another, much more important difference between the two examples. In Forgetful Lethe we consider not only agents (at times) who exhibit de se ignorance, but agents who exhibit no ignorance of any kind, along with important informational links between them (in this case, links of memory). It is precisely by exploiting the relationship between ignorance and its resolution that we will be able to uncover a distinctive case for de se exceptionalism.

Here is an argument, from Lethe's case, against the conjunction of TimelessNess and Temporal Indiscriminateness (given Binary ReLationalism).

(T1) Lethe knows all timeless, temporally indiscriminate, true propositions on Sunday.

(T2) On Monday, Lethe fails to know some proposition that is true (for Lethe on Monday).

(T3) Every timeless, temporally indiscriminate proposition known to Lethe on Sunday is known to Lethe on Monday.

(TC) Some propositions are time-sensitive or temporally discriminate.

(T1) appears trivial if the description of Forgetful Lethe is coherent (though we'll shortly return to the question of whether it is). After all, Lethe is omniscient on Sunday. (T2) seems strong given Binary Relationalism. It is hard to 
deny there is something that Lethe fails to know on Monday. And on the binary relationalist view, that seemingly requires there to be a true proposition (or, more carefully: a proposition true for Lethe on Monday) that Lethe fails to know.

The motivation for $\left(\mathrm{T}_{3}\right)$ - the heart of the argument-will more be complex. I think there are several avenues to demonstrating $\left(\mathrm{T}_{3}\right)$, but a particularly strong one capitalizes on the relationship between Lethe on Wednesday (when his omniscience is restored) and Lethe on Monday.

First, let's add to the story the harmless assumption that Lethe on Monday spends time reflecting on his knowledge, and comes to know whatever he can by simple inferences. It seems that merely by reflecting on his own knowledge Lethe can't escape his predicament: he will continue to be ignorant of whether it is Monday or Tuesday.

Now we'll proceed to show the general claim (T3) by demonstrating the truth of an arbitrary instance. Let $p$ be any timeless, temporally indiscriminate proposition that Lethe knows on Sunday. To simplify and make matters concrete, let's suppose that Lethe thinks this proposition occurrently (and truly) at noon on Sunday. Then the following argument shows that Lethe will know the hypothesized proposition $p$ on Monday.

(tI) On Wednesday, Lethe knows the following proposition $\operatorname{BEL}-\operatorname{Sun}(p)$ : that Lethe truly believes the timeless proposition $p$ at noon on Sunday.

(t2) If Lethe knows $\operatorname{BeL}-\operatorname{Sun}(p)$ on Wednesday, Lethe knows $\operatorname{BeL}-\operatorname{Sun}(p)$ on Monday.

(tc) Lethe knows $p$ on Monday.

Why would (tc) follow? If ( $\left.\mathrm{t}_{1}\right)$ and (t2) hold, then Lethe knows $\operatorname{BEL}-\operatorname{Sun}(p)$ on Monday. Since $p$ is temporally indiscriminate, Lethe can wonder whether $p$ holds on Monday. But by knowing $\operatorname{BeL}-\operatorname{Sun}(p)$, Lethe is in a position to know that $p$ is both timeless and true for Lethe on Sunday. But from this Lethe can infer that $p$ is true at any time-and so a fortiori true 'now'. Lethe knows the a priori conditional: if $p$ is true, then $p$. From all this Lethe can (and by hypothesis does) infer $p$, and can thereby come to know $p$.

More generally, if some $p$ is temporally indiscriminate, and one can now recognize $p$ as both timeless and true (for oneself) at some other time, one is in a position to see that $p$, now.

Now the justification for the premises. There are two interconnected cases for $(\mathrm{t} 1)$. First, Lethe is by stipulation omniscient on Wednesday, and surely the fact that Lethe truly believes a timeless, temporally indiscriminate proposition on Sunday at noon is itself a timeless, temporally indiscriminate proposition, and so a truth for Lethe to know on Wednesday. But there is an equally important case for $\left(\mathrm{t}_{1}\right)$ : Lethe on Wednesday knows by recollection everything relevant to what Lethe 
believed on Sunday at noon. For example, Lethe knows by recollection exactly what it was like to be Lethe on Sunday at noon. We can suppose that Lethe recalls (and can even bring to mind) any phenomenology, including cognitive phenomenology, that Lethe had at that time (or before). Moreover, Lethe knows everything about the physical basis for Lethe's cognitive state-not merely the entire physical make-up of Lethe's brain and nervous system (or whatever is responsible for the god's cognition), but also the physical make-up of Lethe's surroundings, and indeed the entire physical state of Lethe and Lethe's total environment at all times up to and including noon on Sunday. Additionally, Lethe knows the times at which all of the phenomenology and all of the physical events occur, at least under a tenseless description. And Lethe knows any propositions that relate cognitive states to their supervenience bases. It is hard to imagine what more would be needed to settle the truth of the timeless proposition that Lethe believes $p$ at noon on Sunday. If it is possible for anyone, ever to know $\operatorname{BeL}-\operatorname{Sun}(p)$, surely it is possible for Lethe on Wednesday. Finally, Lethe can surely recall Sunday's omniscience on Wednesday to know that what he believed on Sunday, he believed truly.

The point about recollection should perhaps be combined with the point about omniscience. The argument from $\left(t_{1}\right)-\left(t_{3}\right)$ to $\left(t_{c}\right)$ requires that the proposition $\operatorname{BeL}-\operatorname{Sun}(p)$ known by Lethe on Wednesday is in some sense 'directly about' $p$. That is, the proposition must be such that merely by knowing it, and being capable of thinking $p$, one can infer $p$ itself. One might be concerned that perhaps the only sense in which Lethe knows that $p$ was thought on Sunday at noon is 'indirectly' (for example, by some description), so that Lethe is unable to piece together on Wednesday that what was thought was in fact $p$ itself-the would-be conclusion of the Lethe's reasoning mentioned in (tc). But the earlier justification for (T1) will extend to cover this worry (at least until we return to consider (T1) in more detail). If the case is coherent, Lethe knows all true propositions there are to know on both Sunday and Wednesday. So if it is metaphysically possible to know a proposition directly about $p$ on Wednesday, Lethe knows it then. And if Lethe knows it then, it should be possible to know it by recollection in the manner just stated.

This extended case for ( $\mathrm{t} 1$ ) implicitly contains the justification for ( $\mathrm{t} 2$ ). For the very same recollections of Sunday that are available to Lethe on Wednesday are available to him on Monday. Lethe on Monday knows the total phenomenal history of his cognition up to noon on Sunday, by recollection. He knows the entire physical history of the world up to noon on Sunday. Lethe knows tenseless descriptions of when all these events occurred. He knows all supervenience relations between phenomenal/physical states and cognitive states. And Lethe hasn't forgotten that he was omniscient on Sunday. Again, it is hard to know what more information Lethe would need to be able to know $\operatorname{BEL}-\operatorname{Sun}(p)$. 
This concludes the case for $\left(\mathrm{T}_{3}\right)$, and therewith the argument for (TC).

How might we resist the argument? One might try to deny the very first premise $\left(\mathrm{T}_{1}\right)$ which, recall, is:

(T1) Lethe knows all timeless, temporally indiscriminate, true propositions on Sunday.

One way to try to do this would be to deny the coherence of Lethe's omniscience. But I think this maneuver is bound to be ineffectual. There are two kinds of worries one might have for $\left(\mathrm{T}_{1}\right)$. The first concern is that true omniscience is too conceptually demanding to be satisfiable. ${ }^{16}$ But classic versions of this concern (that don't already appeal to de se exceptionalism) trade on epistemic or semantic paradox, or cardinality considerations for the class of propositions. And we can get around these worries by devising a case like Lethe's without requiring omniscience in the strictest sense-all we need is for Lethe to know important 'relevant' propositions, like those concerning the supervenience base for his attitude on Sunday at noon, facts about what times things occur and what time it is presently, and a few a priori facts used in deductions. Lethe can start knowing all true propositions that are 'relevant' in this sense, while losing and regaining only knowledge related to times throughout the four-day period. This will be enough to generate another version of the puzzle. The stipulation of omniscience is merely a helpful simplifying idealization.

There could be a very different worry for ( $\left.\mathrm{TI}_{1}\right)$, namely that there might be propositions that are in-principle inaccessible to Lethe at any time, and these may rob him of omniscience (though this will depend on how we define omniscient). But we can again restrict our attention to a subclass of propositions in-principle knowable to Lethe at some time. Indeed, we can even restrict attention to the (relevant) true propositions Lethe is able to entertain on Sunday at noon. This weakens (T1) substantially. If even Lethe's knowledge of the timeless temporally indiscriminate propositions in that restricted set can be preserved until Monday as in ( $\left.\mathrm{T}_{3}\right)$, we will get the puzzle: Lethe's lack of knowledge on Monday will require there to be a (relevant) proposition Lethe can entertain on Monday. And that unknown proposition cannot be both timeless and temporally indiscriminate, otherwise Lethe could have entertained (and by hypothesis known) it on Sunday at noon.

These same restrictions also block concerns that might be raised for $(t 1)$ in the sub-argument for $\left(\mathrm{T}_{3}\right)$.

(t1) On Wednesday, Lethe knows the following proposition $\operatorname{BeL}-\operatorname{Sun}(p)$ : that Lethe truly believes the timeless proposition $p$ at noon on Sunday.

16. See, for example, the objections to the conceptual coherence of omniscience discussed in Grim (1983). 
$p$ is presumed to be timeless and temporally indiscriminate, so surely $\operatorname{BEL}-\operatorname{Sun}(p)$ is as well. If we accept (T1) but deny (t1), we would have to grant that Lethe can know $\operatorname{BeL}-\operatorname{Sun}(p)$ on Sunday, while having the belief that $p$, but also maintain that Lethe must somehow lose that knowledge on Wednesday, even though Lethe has perfect awareness of his earlier omniscience, and every fact relevant to his beliefs at noon on Sunday, including what time they were held, and 'how long ago' that time was.

If we've granted ( $\mathrm{T} 1)$ and $(\mathrm{t} 1)$, what can we say about ( $\mathrm{t} 2)$ ?

(t2) If Lethe knows $\operatorname{BeL}-\operatorname{Sun}(p)$ on Wednesday, Lethe knows $\operatorname{BeL}-\operatorname{Sun}(p)$ on Monday.

The only difference between Lethe's epistemic position on Wednesday and on Monday is that in the latter Lethe has lost track of the time. But importantly, Lethe still remembers what it was like on Sunday at noon to believe (the timeless, temporally indiscriminate) $p$, the events relevant to the holding of that belief, and even what times all of these events occurred. The only difference is that Lethe doesn't know 'how long ago' all this was. The denier of (t2) would have to claim such information was integral to knowing $\operatorname{BEL}-\operatorname{Sun}(p)$.

Knowing someone's thoughts, even thoughts about themselves, does not seem to be fragile in this unusual way. Suppose that at midnight on New Years Day in the year 2000 you think it is midnight on the first day of the year 2000. On the current view, even if you recall this event and the calendar date on which it occurs with perfect lucidity, you will be perpetually losing and regaining awareness of what you thought that day, as you continue your life and periodically forget and resolve what day it is, or even what time it is. I find it hard to get a grip on why this would be. What's more, it's not even clear that this response to the argument could avoid de se exceptionalism. The lesson it draws about the importance of knowing the time for knowing propositions about agents' beliefs seem to have no analogous motivation in Frege cases. I'm not entirely sure what an analog to this position for ordinary Frege puzzles would be. ${ }^{17}$ So I set this view aside.

Given this, let me recapitulate the dialectic so far. I've claimed that the versions of (T1) and ( $\mathrm{t} 1)$ needed to generate the argument for (TC) are too weak to attack. A version of these worries can be transposed to (t2), but the resulting view is highly unusual, and at any rate wouldn't avoid de se exceptionalism.

17. One possibility is to view the unusual position here as motivated not by analogy with Frege puzzles, but instead by analogy with the epistemic conditions on de re cognition. The idea would be that de re cognition of a past time may require awareness of how long ago that time was. While an intriguing suggestion, this view is powerless to avoid de se exceptionalism. When we generalize the position, it will ultimately endorse one of the strongest exceptionalist positions: the view that each agent has access to a class of proprietary, in-principle unshareable de re propositions about themselves-see Footnote 20. 
If this is right, we are only left with (T2).

(T2) On Monday, Lethe fails to know some proposition that is true (for Lethe on Monday).

I've saved this premise for last because there are two related ways one could resist it. Neither, I think, avoids the brunt of the argument. But seeing why will merit some special attention.

\section{Refining Attitudes}

My defense of (T2) was that it seemed inevitable given BINARY Relationalism. To all appearances, Lethe is ignorant of something on Monday. And what could that be, on the binary relationalist view, if not ignorance of a proposition?

But this leaves two avenues of resistance. First, one could simply deny BInary Relationalism. And as we'll see, once we deny Binary Relationalism, we're actually freed up to say that Lethe does know all propositions on Monday. The reason that Lethe appears to not know a proposition is that Lethe does not know all propositions in all ways one can know them. So we can capture the intuition that Lethe seems ignorant of something, without being committed to his failing to know a particular proposition.

Indeed, there is another view that can make essentially the same maneuver, but without so much as denying Binary Relationalism. This is the view that claims there are multiple kinds of belief or knowledge states. All of these are binary relations to propositions. But sometimes one can appear to be ignorant of a proposition, when in fact one knows that proposition. One knows the proposition, in that one has at least one knowledge state which has that proposition as an object. The problem is just that there may also be at least one important knowledge state taking that proposition as object that one fails to have.

These views are obviously related. And as such, my replies to each will be roughly the same. Let me begin with the denier of BINARY RELATIONALISM.

Suppose that the belief relation is grounded in a ternary believing* relation that relates an agent, a proposition, and a mode of presentation of a proposition. One believes that $p$ just in case there is some mode of presentation under which one believes* it-and likewise for other attitudes. ${ }^{18}$ As always, it is a tricky matter to specify precisely what a mode of presentation comes to. But it is something like a 'way' of thinking a proposition. This view can be used to address Frege's puzzle as follows: When Lois wonders whether Clark Kent is Superman, she

18. I have in mind Salmon (1986). I think it will also be clear from the discussion to follow how the argument can be extended to related accounts such as the 'hidden-indexical' views of Schiffer (1992), Crimmins (1992), Crimmins and Perry (1989). 
may be wondering a proposition she already knows. For the proposition she is wondering may be the trivial singular Russellian proposition $\langle=$, 〈Clark Kent, Clark Kent $\rangle\rangle$. Lois believes* (and 'knows') this proposition under a mode of presentation $m$ on which its triviality is manifest. When she wonders whether Clark Kent is Superman, she wonders* the same singular Russellian proposition, but under a mode of presentation $m^{\prime}$ on which the proposition's triviality is no longer transparent.

This is just a rough sketch of the position. But it will suffice to give a sense of how a ternary relationalist view might be applied to the case of Lethe. Perhaps Lethe knows all the way through his predicament all relevant propositions. Perhaps the proposition Lethe wonders on Monday in asking Is it Monday? is one Lethe already knows-for example as the trivial proposition $\langle=$, 〈Monday, Monday $\rangle$. It's just that Lethe knows this in virtue of knowing* it under some mode of presentation on which its triviality is manifest. The problem is that Lethe may also not know* that proposition under another mode of presentation on which its triviality is not manifest. This accounts for our sense that Lethe is ignorant. But it allows us to deny (T2): Lethe in fact knows all relevant propositions, even on Monday.

What's more, if we block the argument in this way, we have blocked it precisely with resources that have historically been used to treat Frege Puzzles. If this were to occur, the case for de se exceptionalism from cases like Lethe's would be substantially weakened.

But there is an obvious concern. The maneuver here avoids (TC) only by altering an intuitive, pre-theoretic conception of knowledge that we were using to frame the puzzle. Once we see this, it seems like we can recreate the puzzle by simply adjusting it to suit the newly introduced conception of knowledge.

To do this, let's introduce some non-standard terminology. Call a proposition* any pair consisting of a mode of presentation and a proposition such that it is possible for some agent to believe* the proposition under that mode of presentation. Extend the foregoing starred notation for attitudes by saying one knows* a proposition* $p^{*}=\langle m, p\rangle$ just in case one knows* the proposition $p$ under mode of presentation $m$ (and similarly for other attitudes). Call a proposition* $p^{*}=\langle m, p\rangle$ timeless* if at all times, $m$ is a mode of presentation of $p$, and $p$ is timeless. Call $p^{*}$ time-sensitive ${ }^{*}$ otherwise. Call a proposition* $p^{*}=\langle m, p\rangle$ temporally indiscriminate $^{*}$ if, whenever an agent can believe* that proposition* at some time, it is in-principle possible for that agent to believe* that proposition* at any other time. Call $p^{*}$ temporally discriminate* otherwise.

Then we can rerun the argument of $\S 2$ with the relevant terminological variations.

$\left(\mathrm{TI}^{\prime}\right)$ Lethe knows* all timeless*, temporally indiscriminate*, true propositions* 
on Sunday. ${ }^{19}$

$\left(\mathrm{T}^{\prime}\right)$ On Monday, Lethe fails to know* some proposition* that is true (for Lethe on Monday).

$\left(\mathrm{T}_{3}^{\prime}\right)$ Every timeless*, temporally indiscriminate* proposition* known* to Lethe on Sunday is known* to Lethe on Monday.

(TC') Some propositions* are time-sensitive* or temporally discriminate*.

$\left(\mathrm{T}^{\prime}\right)$ is just as strong a premise as before. And as before we can, if we need, drastically weaken the premise while preserving the force of the argument. We can restrict our attention to 'relevant' propositions* that are entertainable* by Lethe on Sunday at noon. If even Lethe's knowledge* of the timeless* temporally indiscriminate* propositions* in that restricted set can be preserved until Monday we will get the puzzle: Lethe's lack of knowledge* on Monday will require there to be a relevant, unknown* proposition* Lethe can entertain* on Monday. And that unknown* proposition* cannot be both timeless* and temporally indiscriminate*, otherwise Lethe could have entertained* (and by hypothesis known*) it on Sunday at noon.

$\left(\mathrm{T}^{\prime}\right)$ is supported by the intuition that Lethe isn't all-knowing (even in a 'relevant' restricted sense) on Monday. Recall that on the views we're currently exploring, even if the appearance of ignorance doesn't always involve failure to know a proposition, it does always involve failure to know* a proposition*. So $\left(\mathrm{T}^{\prime}\right)$ can no longer be denied by appealing to Ternary Relationalism.

And $\left(\mathrm{T}_{3}^{\prime}\right)$ can continue to be supported roughly the same way as before, though the transposition to the new terminology will require the argument to be amended. As before, we'll aim to show the general $\left(\mathrm{T}_{3}^{\prime}\right)$ by demonstrating an arbitrary instance. We begin with the assumption that $p^{*}$ is a timeless*, temporally indiscriminate* proposition* known* to Lethe on Sunday but not known* to Lethe on Monday. Then if we were to try to transpose our earlier argument to the new case, the best reformulation would be as follows.

$\left(\mathrm{t} 1^{\prime}\right)$ On Wednesday, Lethe knows the following proposition $\mathrm{BEL}^{*}-\mathrm{SuN}\left(p^{*}\right)$ by perfect recollection: that Lethe truly believes* the timeless* proposition* $p^{*}$ at noon on Sunday.

$\left(\mathrm{t} 2^{\prime}\right)$ If Lethe knows $\operatorname{BEL}^{*}-\operatorname{Sun}\left(p^{*}\right)$ by perfect recollection on Wednesday, Lethe knows $\mathrm{BEL}^{*}-\mathrm{SuN}\left(p^{*}\right)$ by perfect recollection on Monday.

$\left(\mathrm{tc}^{\prime}\right)$ Lethe knows* $p^{*}$ on Monday.

19. Where a proposition* is true (at a time, for an agent) if its component proposition is true (at that time, for that agent). 
Note two subtleties: knows in premises $\left(\mathrm{t}^{\prime}\right)-\left(\mathrm{tz}^{\prime}\right)$ is intentionally not starred, while it is in $\left(\mathrm{tc}^{\prime}\right)$. Also I have added how Lethe knows relevant propositions-by perfect recollection. This will be important because it gives us information about the kind of mode of presentation under which Lethe knows about his past beliefs. Why that is important will become clearer shortly.

It is worth going through the justification for all steps. $\left(\mathrm{t}^{\prime}\right)$ is again motivated by the idea that $\mathrm{BEL}^{*}$-SuN $\left(p^{*}\right)$ is timeless and temporally indiscriminate (note: no starring) in part because $p^{*}$ is timeless* and temporally indiscriminate* When Lethe recalls what it was like on Sunday at noon to occurrently and truly believe* $p^{*}$, surely Lethe can come to believe (no starring) that he then truly believed* $p^{*}$. After all, Lethe must have at least one mode of presentation under which he can currently think about $p^{*}$ (indeed, something stronger should hold: since that proposition* is temporally indiscriminate*, Lethe can currently entertain* $p^{*}$ 'directly'). And as before this case can be bolstered with the intuitive thought that by Wednesday Lethe has been restored to whatever kind of omniscience (however limited) that he enjoyed on Sunday.

$\left(\mathrm{tz}^{\prime}\right)$ extends the case for $\left(\mathrm{tr}^{\prime}\right)$ as before: Lethe on Monday has exactly the same access to facts about Sunday at noon that he has on Wednesday-including recollection of believing* $p^{*}$, and all physical and phenomenal facts constituting his belief* in $p^{*}$. To accept $\left(\mathrm{tr}^{\prime}\right)$ but deny $\left(\mathrm{tz}^{\prime}\right)$, one would have to maintain that losing track of the time puts Lethe out of touch with any mode of presentation under which he could recognize $\operatorname{BeL}^{*}-\operatorname{Sun}\left(p^{*}\right)$. As before, in addition to its implausibility, it is not clear how this view would avoid de se exceptionalism.

Now a complication: how can we get from $\left(\mathrm{tr}^{\prime}\right)-\left(\mathrm{tz}^{\prime}\right)$ to $\left(\mathrm{tc}^{\prime}\right)$ ? The premises attribute knowledge about $p^{*}$. That is, knowledge* about $p^{*}$ under some mode of presentation or other-in this case, whichever modes are involved in recollection of thought. But we need a conclusion about knowledge* of the propositional component of $p^{*}$ under the relevant specific mode of presentation in $p^{*}$.

In the argument of $\$ 2$, we transitioned from (t1)-(t2) to (tc) merely by appeal to Lethe's knowledge of a simple conditional if $p$ is true, then $p$. But it is not entirely clear what the analogous principle should look like when talking of mode of presentation/proposition pairs. (Note that if $p^{*}$ is true, $p^{*}$ may simply be nonsense given that $p^{*}$ is an ordered pair.) Still, I think there is plausible (if convoluted) bridge principle that will suffice for Lethe's particular case.

(X) For all logically competent agents $A$, propositions $p$, and modes of presentation $m$ if the following hold:

- A perfectly recalls believing* $p$ under mode of presentation $m$, and that this believing* constituted knowledge*;

- A knows that in so-believing*, she believed* under a mode of presentation which always denotes the same timeless proposition; 
- $A$ is now capable of entertaining* $p$ under mode of presentation $m$;

then $A$ is in a position to now believe* $p$ under mode of presentation $m$, and have that belief* constitute knowledge* that $p$ under $m$.

The formulation here is convoluted, in part to create a weak principle: each clause is ruling out an excuse for the agent to not be in a position to know ${ }^{*} p$ under $m$. But the idea behind the principle is simple. For example, suppose Lois is now wondering whether Clark Kent is Superman. On the view we're exploring, she wonders* a trivial Russellian proposition $\langle=,\langle$ Clark Kent, Clark Kent $\rangle\rangle$ under a mode of presentation $m^{\prime}$ on which its triviality is not manifest. But suppose at some previous time Lois came to know* Clark Kent was Superman under $m^{\prime}$. Perhaps she was told they were the same. Perhaps she saw Clark put on Superman's clothes. Now consider the moment she had the occurrent belief* under $m^{\prime}$ (the belief that she would express by saying Clark is Superman). And suppose she presently comes to recall what it was like to have that belief*, under that mode of presentation, with perfect clarity. Can she now resolve whether Clark Kent is Superman? Surely this is possible-surely this is just to recall that she knew Clark is Superman in an intuitive sense, which is what knowledge* of the trivial Russellian proposition under $m^{\prime}$ is tracking. And it seems for any case of ignorance of identity that doesn't involve ignorance of time or place, including 'demonstrative' ignorance of identities, we can recreate a similar scenario.

The reason for thinking that $(\mathrm{X})$ holds is that recollecting perfectly what it is like to think some proposition under a mode of presentation seems to put one back in touch with that mode of presentation. Whatever a 'way of thinking' comes to, there is pressure to associate those 'ways of thinking' with the cognitive positions that we occupy during thought. If we can retrieve those cognitive positions through memory, as seems plausible, then we should be in a position to re-think under those modes of presentation. And if we know that what we once thought was true, and that what we thought doesn't change its truth-value over time, it seems our current thoughts should be able to count as knowledge of what we thereby currently think.

Once we see this simple motivation for $(X)$, we see the simple motivation for drawing the inference from $\left(\mathrm{ti}^{\prime}\right)-\left(\mathrm{t} 2^{\prime}\right)$ to $\left(\mathrm{tc}^{\prime}\right)$. And with that inference we conclude our argument for $\left(\mathrm{TC}^{\prime}\right)$. As such the denial of BinaRy Relationalism hasn't avoided our puzzle concerning the de se, but merely driven us to reformulate the terms in which the puzzle is stated.

Let me recapitulate what I take to be the general lesson of this discussion. In $\S 2$, I constructed an argument against the conjunction of TIMELESSNESS and TEMPORAL INDISCRIMINATENESS which was motivated by a simple idea: it seemed that one could have been omniscient, and could now perfectly recollect that omniscience, without presently being in a position to know everything. This is 
neatly explained if Timelessness or Temporal Indiscriminateness fail. For example if Timelessness fails, then if one perfectly recalls knowing propositions true only for one's past self, there is no guarantee that will be of help in learning all the propositions true for one's present self. Or if Temporal IndiscriminateNESS fails, then perhaps there are propositions that one can entertain now that one simply couldn't in the past. If so, recollecting knowledge of all the propositions that one could know at the previous time wouldn't suffice for knowing all propositions that one could now know. I argued that it wasn't clear there was any other plausible way to explain how one could pass from omniscience to ignorance in the constrained way described.

The current attempt to avoid that argument by denying the agent's omniscience of the time didn't really engage with these concerns-it merely shifted around what counts as 'knowledge' (knowledge not of a proposition, but a proposition under at least one mode of presentation) and thereby what it was to count as ignorant or omniscient. But precisely because it doesn't engage with the core worries raised by the argument, it seems the argument can be reconstructed. It mostly requires rephrasing the ideas of the argument in a new idiom.

I began this section by noting there were two ways of resisting (T2).

(T2) On Monday, Lethe fails to know some proposition that is true (for Lethe on Monday).

The first avoids (T2) by embracing Ternary Relationalism, and has been dealt with. But I have yet to consider the second route for rejecting (T2), which maintains Binary Relationalism. According to this view, there are multiple kinds of knowledge states, and on Monday Lethe knows all propositions by possessing at least one kind of knowledge state for each proposition to be known. The impression of ignorance is accounted for by Lethe's failing to know some proposition in some state of knowledge.

This view is structurally similar to the ternary relationalist view. Instead of (in some sense) refining possible attitudes by adding modes of presentation under which propositions are believed or known, the new view posits more attitude states-intuitively a new state of belief or knowledge for each mode of presentation we might have posited on the earlier view. And just as one knows a proposition on the earlier view if one knows it under one mode of presentation, one knows a proposition on the new view if one knows it as part of one kind of knowledge state.

It turns out that this view presents no new challenges. We can recast our terms to recreate a parallel argument for this view in almost exactly the way we did for the ternary relationalist-let me just briefly sketch it. Say that an attitude state is timeless ${ }^{* *}$ if there is a timeless proposition $p$, such that any time an agent is in the attitude state, it takes $p$ as an object. Say the attitude-state 
is time-sensitive** otherwise. Say an attitude-state is temporally indiscriminate** if, whenever an agent can get into that attitude state at some time, it is in-principle possible for that agent get into that attitude state at another time. Say the attitudestate is temporally discriminate** otherwise.

Then we can apply pressure to the claim that all attitude states are timeless** and temporally-indiscriminate** in an increasingly familiar way. We start by supposing Lethe, on Sunday, is in all the timeless** knowledge states that it is possible for him to be in on Sunday, and claim that the appearance of ignorance on Monday must be explained by his lacking some knowledge** state that he could be in on Monday. Then we argue that any timeless** temporally indiscriminate** knowledge state he is in on Sunday is one he can get into with the help of perfect recollection on Monday. This will require a bridge principle roughly like $(\mathrm{X})$ : perfect recollection of being in a state of timeless ${ }^{* *}$ knowledge enables one to be in that state now, provided one can be. As before, the suspicion is that this principle will look eminently plausible however we cash out the notion of a fine-grained attitude-state-at least for cases that don't involve de se attitudes. And that will be enough to pressure the move to de se exceptionalism.

It is worth mentioning that the view I've just been discussing, on which we must refine attitude states at least some of the time, is a version of a view endorsed by Perry (1979). Perry argued from cases of de se ignorance and the role of de se attitudes in action that this kind of refinement of attitude states was necessary. I do not think Perry's arguments succeed. But more importantly, even if we take this view, this is not what is important about the position that Perry ends up with. Rather it is the fact that Perry couples his view with a denial of Timelessness**. For Perry, an individual can get into the exact same belief state at different times and believe truly the first time and falsely the second. This is not possible if all attitude states are timeless** ${ }^{20}$

20. I want to mention an objection, and associated reply, that doesn't fit neatly into the foregoing dialectic. The objection focuses not on analogies between de se ignorance and Frege puzzles, but on analogies between de se and de re thought. On many theories of de re cognition, one must bear some appropriate cognitive relation to an object in order to have de re thoughts about it. Such views raise a concern. For on them, propositions about all sorts of objects-not merely about times and the self-cannot be entertained by agents who fail to be 'appropriately cognitively situated'. And this may seem to undermine the special character of the de se, provided one reacts to my arguments by denying Temporal InDiscriminateness. After all, times (and eventually presumably 'selves') would then simply be further objects for which some version of the cognitive situatedness requirement held. It would just turn out (say) that existing at, or past, a particular time is the only way to be cognitively situated to have de re thoughts about that time.

There are two points, one weaker and one stronger, to make about this concern. The first, weaker point leans on the caveat made earlier that de se exceptionalism should be viewed as established in degrees, based on how many views are forced to make adjustments in light of the peculiarities of self-directed thought. The view just glossed on which it is in-principle 


\title{
4. Two Gods Revisited
}

I've focused so far on the role of time in what makes de se belief special. But we can equally motivate a special role for agenthood. The argument relies on some simple modifications of Lewis's Two Gods. But though the modifications may appear slight, it is worth stressing that they aren't dispensable. Indeed, as I'll discuss in more detail in \$5, their omission in Lewis's original version is precisely what deprives him of any persuasive case for de se exceptionalism.

As before, we need some definitions. Call a proposition egalitarian if its truth or correctness does not vary from agent to agent, and inegalitarian otherwise. Call a proposition agentially indiscriminate if for every time, if one agent can think that proposition at that time then it is in-principle possible for any other agent to think that proposition at that time as well. Call the proposition agentially discriminate otherwise. Then we have the following three tempting theses about propositional attitudes.

\section{Binary Relationalism (about Attitudes)}

An attitude like belief is a binary relation between an agent and a proposition, not grounded in any attitude state of higher adicity.

\section{Egalitarianism (of Mental Content)}

The propositional objects of attitudes are egalitarian.

\section{Agential Indiscriminateness (of Mental Content)}

The propositional objects of attitudes are agentially indiscriminate.

\begin{abstract}
impossible to have de re thoughts about a time until it arrives is a highly restrictive view of de re thought in relation to time. Consider how much information Lethe can have about future times on Sunday: he could have de re information, of every existing particle, where it will be at noon Monday (and before, and after), de re information about the current time, and all information about the laws of nature. Can he really not have de re thoughts about noon on Monday? A view that forbids this in a principled way will likely have to posit extreme general restrictions on the availability of de re thought by indirect means. If we can only escape the positions exceptionalists have advanced by committing ourselves to this type of view, exceptionalism will have still been established to some noteworthy degree.

But we needn't end things there, as there is a stronger point to be made based on the analogies between times and persons. In the next section, I'll argue that a parallel argument to Lethe's can be constructed for ignorance of 'who one is'. Trying to explain the problems by a 'situatedness' requirement on ordinary de re belief will require that there are some thoughts about an agent-a special class of de re thoughts about them-that one could only ever be positioned to have by being that very agent. There is no plausible sense in which this view avoids exceptionalism. Not only are such absurdly narrow restrictions on the shareability of thoughts absent from any ordinary cases of de re belief, but the resulting view is no different from the most extreme form of de se exceptionalism—-that embraced by Frege. I'm grateful to Mike Caie for pushing me to clarify this point.
\end{abstract}


As before, the focus of the argument will be on Egalitarianism and Agential InDisCRIMINATENess, with Binary Relationalism acting as a simplifying assumption.

Now, a natural way to construct an argument against EgALITARIANISM and Agential InDisCRIMINATENESS that paralleled the arguments of $\$ \S 2-3$ would be to have a god-like agent pass between total omniscience (or something close enough) to ignorance of 'who they are', and back to omniscience. Then we could try to argue that the recollection of omniscience is unhelpful to the god while ignorant. The problem is that this mixes issues about agential shareability or constancy with temporal shareability or constancy. In other words, such a case would make it hard to apply pressure to Egalitarianism and Agential IndisCRIMINATENESS alone, as opposed to their conjunction with TIMELESSNESS and Temporal InDiscriminateness. To avoid this intermingling, it would be best to have all relevant mental states of the god in question appear at a single time. But obviously we can't do this while continuing to lean on some of the unique epistemic features of memory that were helpful for my previous arguments.

I think the best way out of these complications is to stick to a case where all mental states occur at one time. This makes the argument for the unique features of agenthood in the de se somewhat more unusual than that of $\S \S 2-3$. But I think that once we see the parallels between the case against Timelessness and Temporal Indiscriminateness, and that against Egalitarianism and Agential INDISCRIMINATENESS, any special concerns for the argument against the latter are dismissible on grounds of parity. That is one reason I think it is important to treat the temporal case first.

With that in mind, here is the case.

Arsu And AzIzos

Twin gods Arsu and Azizos find omniscience dreary. They drink a tea inducing a limited form of amnesia: when they wake they will intuitively continue to know 'impersonal' facts (including that Arsu and Azizos exist, where they are at various times, and so forth). But they will forget 'who they are' so that each upon waking will wonder what they would express by saying Which god am I, Arsu or Azizos? That ignorance is accompanied by ignorance of 'where they are'. For when the gods wake, their surroundings will be subjectively indistinguishable. Because each god is so similar, when they wake they will perform exactly the same actions in exactly the same way at the same time. Eventually they will both walk north. Arsu will see a camel, at which point his ignorance will be resolved: he will know he is Arsu. For at the same moment Azizos will see a horse, and have his ignorance resolved. What is more: Arsu and Azizos have a special godlike 
power. They have the ability to get perfectly reliable visions from any part of space or time that they can think of in impersonal terms (for example relative to its date, or its location on a map). They can, and indeed do, freely exercise this ability when they wake. The catch is, of course, that whenever they exercise this ability just after waking, they do so at the same time and in the same way. Finally, while all this is taking place, off in the distance and out of sight of Arsu and Azizos, a different, fully omniscient god Monimos will observe all that takes place.

Here is the rough idea behind the case: Monimos stands to Arsu (or Azizos), like Sunday- and Wednesday-Lethe stand to Monday-Lethe (or Tuesday-Lethe) in Forgetful Lethe. And the ability of Arsu (or Azizos) to get accurate visions tied to a particular time and place (impersonally characterized) is meant to be the analog of Lethe's ability to retrieve information about the world through memory of his past thoughts (picked out tenselessly). Indeed, the ability of Arsu to get accurate visions of what Monimos is thinking will be critical to creating parallels to the arguments of $\S \S 2-3$.

Let us add to the story the harmless assumption that Arsu (and so Azizos) upon waking uses his abilities to their fullest potential, extracting from his visions all the information he can, including by simple inferences. As before, the impersonal character of the information seems unhelpful in resolving the god's ignorance. Arsu may say: reveal Arsu now! and thereby come to have a vision of himself, transfixed in a vision of Arsu. The problem is that Azizos is having the same vision at the same time, and nothing in the vision allows Arsu to distinguish that the person he is seeing is himself. Similarly Arsu may say: reveal Monimos now! and thereby come to have visions of Monimos obeserving the two gods and thinking about them. Again, since Azizos has the same vision at the same time, none of this allows Arsu to resolve his ignorance. If Arsu could only say: reveal me now! he would be in a position to use his abilities to resolve his ignorance. But we are supposing that his abilities don't allow this.

Now, focusing on a particular time $t$ after which Arsu has awoken and exercised his abilities to their fullest, we can argue against the conjunction of EGALitarianism and Agential Indiscriminateness (given Binary Relationalism) as follows.

(A1) Monimos knows all egalitarian, agentially indiscriminate, true propositions at $t$.

(A2) At $t$, Arsu fails to know some proposition that is true (for Arsu at $t$ ).

(A3) Every egalitarian, agentially indiscriminate proposition known to Monimos at $t$ is known to Arsu at $t$. 
(AC) Some propositions are inegalitarian or agentially discriminate.

(A1) follows from the coherence of Monimos's omniscience though, as before, it may be helpful to weaken the description of the case and premise so that Monimos knows all 'relevant' propositions that are knowable to him at $t$. Even then, provided Arsu fails to know some proposition at $t$ as per (A2), that proposition cannot be egalitarian and agentially indiscriminate, otherwise Monimos could believe and know it at $t$ which would contradict ( $\left.\mathrm{A}_{3}\right)$.

(A2) is justified intutively, though we'll have more to say about it shortly. And (A3) can be justified as follows: Let $p$ be some egalitarian, agentially indiscriminate proposition known to Monimos but not known to Arsu at $t$. Suppose, for simplicity, that Monimos has this belief occurrently at $t$. Then:

(a1) At $t$, Monimos knows the following proposition $\operatorname{BeL}-\operatorname{Mon}(p)$ : that Monimos truly believes the egalitarian proposition $p$ at $t$.

(a2) If Monimos knows Bel-Mon $(p)$ at $t$, then Arsu knows Bel-Mon $(p)$ at $t$.

(ac) Arsu knows $p$ at $t$.

(a1) simply requires that Monimos knows ('directly') both what he is thinking while he is thinking it, and that what he is thinking is a true egalitarian proposition. (a2) is justified by Arsu's being able to get all 'impersonal' information about Monimos, including any physical basis for his belief. What's more, we could even add, if we like, that the information Arsu gets through his 'visions' can be used to get phenomenal information about Monimos-for example, the ability could be used to 'bring to mind' the kinds of experiences that Monimos is having at $t$. Even this kind of information is insufficient to resolve Arsu's ignorance. But it (perhaps in conjunction with the other impersonal information) should be sufficient for Arsu to get awareness of what proposition Monimos is thinking at $t$. For example, it seems to exhaust the kind of information that Monimos has about his own belief state. Finally, the transition between (a1)-(a2) and (ac) can be justified as follows: (a1) and (a2) entail that Arsu knows BeL-Mon( $p$ ). And from that knowledge Arsu can surmise that $p$ is true simpliciter, and thereby come to know $p$ itself.

The argument is of course just like that involving Lethe. The main difference is that what Lethe comes to know from memory Arsu may have to come to know through his unusual ability to conjure visions of the world around him. I suspect some readers may view the unusual character of Arsu's ability, and its role in the argument, with suspicion. And I would concede that such worries could have some force to the extent that ARSU AND AzIzos is considered in isolation. But when the case is compared with Forgetful Lethe, in which we have a much more familiar kind of trans-temporal access to mental states that is the parallel 
of Arsu's inter-agential awareness, I feel there is a very strong case for thinking that the two examples stand or fall together. It is a frustrating feature of Arsu's case that we must posit his unusual form of divine awareness to get the example up and running. But once we see that it is merely supposed to be the analog of memory, I think it is hard to maintain that we should treat the trans-temporal and inter-agential cases in any significantly different way.

As for our earlier (T2), the case of (A2) requires a little more commentarybut the commentary is not really different than before.

(A2) At $t$, Arsu fails to know some proposition that is true (for Arsu at $t$ ).

We can deny (A2) by embracing Ternary Relationalism, or by refining attitude states as Perry suggested. But these denials merely shift the bump in the rug. Once we alter our conception of attitude states, we will be able to revamp the argument to apply pressure to corresponding theses about agential invariance EgALITARIANISM* and AgEntial INDISCRIMINATENESs*, or EgAlitariANISM $^{* *}$ and AgENTIAL INDISCRIMINATENESs**. Since nothing important changes in the transposition (beyond the points already covered for Lethe), I'll leave a detailed discussion of these maneuvers aside.

In brief, if the case against Timelessness and TEMPORAL INDISCRIMINATENESS from Forgetful Lethe has any force, so too does the case against EgALITARIANism and Agential Indiscriminateness from Arsu and Azizos. Thus, as de se exceptionalists have historically maintained, the dimensions of time and agenthood do seem to have a distinctive role in our understanding of propositional attitudes.

\section{Why is De Se Belief Special?}

I've maintained that the lessons I've been drawing from my examples aren't similarly motivated by ordinary Frege cases. It's worth reminding why. My examples most fundamentally raise questions about whether certain attitudes are helpful to share, or possible to retrieve, across time or between persons. The puzzles posed by ordinary ignorance of identity don't seem to raise any such challenges. One can remember that one truly believed that Hesperus is Phosphorus, and thereby come to know that Hesperus is Phosphorus now. One can learn that someone else believes truly that Hesperus is Phosphorus, and thereby come to know this oneself. It is only when we try to have attitudes characteristically about selves reach across time, or across persons, that the distinctive problems for de se attitudes come into view.

The problem of the de se that can be made salient by (pure) de se ignorance is not merely another version of the problems raised by Frege's puzzles. ${ }^{21}$ The

21. Note: I am not claiming my cases do not involve Frege puzzles. Perhaps they do. The 
latter puzzles essentially raise problems about the 'fineness of grain' of attitudinal content (or attitudes themselves). But as we saw, the puzzles raised by de se ignorance persist, sometimes in slightly altered form, as we refine content or attitudes states. Indeed, they persist in a manner that seems largely indifferent to how far the refinement in content or attitudes goes.

Seen from this perspective, both Lewis and Perry may have given misleading presentations of what was special about de se attitudes. Lewis billed them, in part, as forcing us to refine attitudinal content. Perry billed them, in part, as forcing us to refine attitude states. Though perhaps one or the other of these views should ultimately be endorsed, they do not on their own capture what was distinctive about de se attitudes.

Indeed, as Lewis refined attitudinal content, he concurrently embraced two other theses: the denial of Timelessness and Egalitarianism. And as Perry refined attitude states, he concurrently denied Timelessness** and EgalitariAnIsm $^{* *}$. Denying Timelessness and Egalitarianism prevents useful transfer or sharing of attitudinal content: even if content true for someone at some time can be shared, there is no guarantee that the truth of the content will persist through the sharing. Denying Timelessness** and Egalitarianism ${ }^{* *}$ likewise prevents the useful transfer or sharing of attitudinal states: even if a state can be shared that takes some true content as object (for someone at some time), there is no guarantee that the truth, or even the content, of the attitude will persist through the sharing. And there are of course also more extreme routes taken by other exceptionalists, as with Fregean denials of Agential IndiscriminateNESS that preclude the very possibility of sharing certain contents altogether. It is these kinds of denials of useful shareability and transfer that are characteristically motivated by de se attitudes. And these denials are to an important extent conceptually separable from the other proposals that Lewis and Perry were making, like those to refine content or refine attitude states.

So it is not that Lewis or Perry (or any other exceptionalist) failed to broadly identify some features that make de se attitudes representationally special. The concern is rather that their arguments for exceptionalism did little to capitalize on those features by raising questions about useful sharing or transfer. Instead their arguments tended to focus only on how the de se might force us to refine content or attitude states. This subtle mingling of questions of refinement with issues of sharing and transfer thus obfuscated the characteristic features of the de se, while also substantially weakening the case for de se exceptionalism. We can see this, I think, quite clearly in Lewis's case.

Consider, for example, how Cappelen and Dever reasonably recast the argument implicit in Lewis's discussion of Two Gods.

point, again, is that ordinary Frege puzzles do not characteristically raise troubles for theses of shareability or retrievability, whereas cases of essential de se ignorance do. 
P1: Each god knows (ex hypothesi) every true [possible worlds] proposition.

P2: Neither god knows which of the two gods he is, or which mountain he lives on.

$\mathrm{P}_{3}$ (tacit): Which god he is or which mountain he lives on, is something for each god to know.

$C_{1}$ : Neither god knows everything.

C2: There is some knowledge that is not knowledge of a true [possible worlds] proposition. (Cappelen and Dever, 2013, 88)

Note that possible worlds propositions are, by definition, timeless and egalitarian. So establishing that there are more objects of attitudes than possible worlds propositions, as in (C2), might seem to cut against Timelessness and EgalitariANISM. And indeed Lewis seems to have taken his case, and implicit argument, in this spirit. For he took his example to motivate the centered worlds framework for mental content, which requires the falsity of Timelessness and EgaLitarianISM.

But the argument here attributed to Lewis is weak-indeed simply question begging-if its aim is to apply pressure to theses like Timelessness and EgaliTARIANISM. The reason is simple: we get from ( $\left.\mathrm{C}_{2}\right)$ to the denial of TIMELESSNESS and Egalitarianism only on the added assumption that possible worlds propositions are the only objects of attitudes that are timeless and egalitarian. But why think that? Certainly nothing in Lewis's thought experiment motivates such a claim. And the work here is non-trivial. Why not think, to take one of many examples, that timeless, egalitarian Fregean propositions are what is needed to explain the source of the two gods' ignorance?

This critical gap is precisely where de se skeptics have rightly objected to the efficacy of Lewis's argument. It at best establishes (C2), and thereby that there are more objects of attitudes than possible worlds propositions. But all sorts of examples having nothing to do with the de se seem to motivate (C2) with roughly equal force. And as I've been at pains to stress, such a conclusion doesn't immediately bear on whether we should deny TIMELESSNESS or EgaLITARIANISM. So Lewis's example and argument does nothing to establish the features of de se thought that make them representationally special. This is so even though Lewis ultimately helped himself to a framework which happened to integrate some of those representationally special features.

What is more, it is not clear how Lewis could have used his case to uncover the distinctive features of de se thought. Those distinctive features are about shareability or transfer. As already noted, if EgalitaRIANISM fails then'transferring' a self-directed thought that is true for you won't necessarily help me resolve 
my ignorance about the corresponding self-directed thought. And if Agential INDISCRIMINATENESS fails, the relevant self-directed thought can't be transferred to begin with. The problem is that there is no aspect of Lewis's example which bears on the question of shareability or transfer.

To bring out these issues, accordingly, we need to introduce elements that raise questions about shareability and transfer-not only agents exhibiting de se ignorance, but one or more agents who have relevant de se attitudes to share in order to resolve the ignorance (if possible), and conditions for the sharing to take place. These were precisely the added features in Forgetful Lethe and ARsu AND AzIzos. In both cases, we introduced an agent who was in possession of all possibly relevant information, including de se information-whether this was a different agent, or merely the same agent at a different time. And we also introduced the conditions for the sharing of that information-conditions of perfect recollection of one's past mental states, or conditions to know the concurrent mental states of another. When ignorance cannot be resolved under these very specific conditions, only then do we have the features in place to uncover the distinctive representational properties of the de se.

In sum, de se attitudes are not representationally special because of a problem of refinement. They are special because thought about what time it is and what person one is has a special perspectival nature that interferes with sharing or transfer. Attitudinal content with that perspectival nature may indeed be different from other kinds of content. But it is not merely because we need 'more' contents to account for de se thought that such thought is special. On the contrary, that is perhaps the least interesting thing about it.

Though I won't discuss the issue here, I think that Perry, like Lewis, is guilty of obscuring the relative unimportance of attitudinal refinements in accounting for de se thought, in ways that make it hard to see how he could have established the unique features of de se thought from his examples of de se ignorance. Instead I want to conclude by giving credit to an author who does not as clearly share in this guilt: Frege. For all the perplexities ones finds in Frege's work on first-person thought, one cannot accuse him of failing to highlight the distinctively perspectival features of such thought. As we had occasion to note in $\S_{1}$, Frege overtly denies Agential Indiscriminateness, for reasons having nothing to do with issues of fineness of grain. ${ }^{22}$ Even if arguments for such a position in Frege's works are found wanting, we should give some credit where it is due. This is important because not only are Frege's views on the first-person often criticized on their own terms, but now de se skeptics have heaped on that criticism the concern that Frege simply blundered in failing to see his own celebrated informational puzzles when they stared him in the face for a second time. But

22. And on some readings, he should have denied Temporal Indiscriminateness as well—see (Kripke, 2011, 303). 
far from being guilty of this blunder, Frege seems to have glimpsed, however indistinctly, through to what makes thoughts about ourselves representationally special, right from the start.

\section{Acknowledgments}

I'm grateful to David Braun, Mike Caie, Dmitri Gallow, Dilip Ninan, Japa Pallikkathayil, an audience at the Hebrew University of Jerusalem, and several anonymous reviewers for feedback on this material.

\section{References}

Boer, Steven E. and William G. Lycan (1980). Who, Me? Philosophical Review, $89(3), 427-66$.

Brogaard, Berit (2012). Transient Truths: An Essay in the Metaphysics of Propositions. Oxford University Press.

Cappelen, Herman and Josh Dever (2013). The Inessential Indexical: On the Philosophical Insignificance of Perspective and the First Person. Oxford University Press.

Castañeda, Hector-Neri (1966). 'He': A Study in the Logic of Self-Consciousness. Ratio, 8, 130-57.

Castañeda, Hector-Neri (1967). Indicators and Quasi-Indicators. American Philosophical Quarterly, 4(2), 85-100.

Castañeda, Hector-Neri (1968). On the Logic of Attributions of Self-Knowledge to Others. Journal of Philosophy, 65(15), 439-456.

Chalmers, David J. (2011). Propositions and Attitude Ascriptions: A Fregean Account. Noûs, 45(4), 595-639. https://doi.org/10.1111/j.1468-0068.2010.00788. $x$

Crimmins, Mark (1992). Context in the Attitudes. Linguistics and Philosophy, 15(2), 185-198.

Crimmins, Mark and John Perry (1989). The Prince and the Phone Booth: Reporting Puzzling Beliefs. Journal of Philosophy, 86(12), 685-711.

Devitt, Michael (2013). The Myth of the Problematic De Se. In Neil Feit and Alessandro Capone (Eds.), Attitudes de Se: Linguistics, Epistemology, Metaphysics (133-162). CSLI Publications.

Douven, Igor (2013). The Epistemology of De Se Beliefs. In Neil Feit and Alessandro Capone (Eds.), Attitudes de Se: Linguistics, Epistemology, Metaphysics (273289). CSLI Publications.

Elga, Adam (2000). Self-Locating Belief and the Sleeping Beauty Problem. Analysis, 6o(2), 143-147. 
Evans, Gareth (1981). Understanding Demonstratives. In Herman Parret (Ed.), Meaning and Understanding (280-304). Clarendon Press.

Frege, Gottlob (1997). On Sinn and Bedeutung. In Michael Beaney (Ed.), The Frege Reader (151-171). Blackwell. (Original work published 1892)

Frege, Gottlob (1997). Thought. In Michael Beaney (Ed.), The Frege Reader (325345). Blackwell. (Original work published 1918)

Grim, Patrick (1983). Some Neglected Problems of Omniscience. American Philosophical Quarterly, 20(3), 265-277.

Heck, Richard (2002). Do Demonstratives Have Senses? Philosophers' Imprint, 2(2), 1-33.

Kripke, Saul A. (2011). The First Person. In Philosophical Troubles. Collected Papers Volume I (292-321). Oxford University Press.

Lewis, David (1979). Attitudes de Dicto and de Se. Philosophical Review, $88(4), 513-543$.

Magidor, Ofra (2015). The Myth of the De Se. Philosophical Perspectives, 29(1), 249283.

McDowell, John (1984). De Re Senses. Philosophical Quarterly, 34(136), 283-294.

Ninan, Dilip (2016). What Is the Problem of De Se Attitudes? In Stephan Torre and Manuel Garcia-Carpintero (Eds.), About Oneself: De Se Thought and Communication (86-120). Oxford University Press.

Perry, John (1977). Frege on Demonstratives. Philosophical Review, 86(4), 474-497.

Perry, John (1979). The Problem of the Essential Indexical. Nô̂s, 13(1), 3-21.

Richard, Mark (1981). Temporalism and Eternalism. Philosophical Studies, 39(1), 1-13.

Salmon, Nathan (1986). Frege's Puzzle. Ridgeview.

Schiffer, Stephen (1992). Belief Ascription. Journal of Philosophy, 89(10), 499-521.

Shaw, James R. (2015). De Re Belief and Cumming's Puzzle. Analytic Philosophy, 56(1), 45-74.

Spencer, Cara (2007). Is There a Problem of the Essential Indexical? In Michael O'Rourke and Corey Washington (Eds.), Situating Semantics: Essays on the Philosophy of John Perry (179-198). MIT Press.

Torre, Stephan (2018). In Defense of De Se Content. Philosophy and Phenomenological Research, 97(1), 172-189. https://doi.org/10.1111/phpr.12364 